\title{
AVALIAÇÃO DE VARIÁVEIS OPERACIONAIS PARA ELETRODEPOSIÇÃO DE LIGAS METÁLICAS DE Ni-Co-W
}

\section{Giovana Silveira Lisbôa*, Daniella Golçaves Portela, Ambrósio Florêncio de Almeida Neto.}

\begin{abstract}
Resumo
Neste trabalho, foi determinado como a densidade de corrente elétrica e a agitação do banho eletrolítico influenciaram a composição química, morfologia e cristalinidade das ligas de Ni-Co-W. As eletrodeposições foram realizadas variando as densidades de corrente elétrica entre $50 \mathrm{~mA} / \mathrm{cm} 2$ e $70 \mathrm{~mA} / \mathrm{cm} 2$ e as velocidades de rotação catódica entre 20 rpm e 60 rpm. Para a avaliação dos resultados, utilizou-se as eficiências de deposição, análise química por Energia Dispersiva de Raios X (EDX), morfologia por Microscopia Eletrônica de varreduara (MEV) e cristalinidade por Difração de Raios X (DRX). Concluiu-se que elevadas densidades de corrente provocaram poucas alterações ao nível estrutural, morfológico e de eficiência de deposição das ligas de Ni-Co-W.
\end{abstract}

\section{Palavras-chave:}

Eletrodeposição, Ni-Co-W, densidade de corrente.

\section{Introdução}

Ligas metálicas de $\mathrm{Ni}$-Co apresentam propriedades magnéticas, condutividade térmica, resistência ao desgaste e atividade eletrocatalítica e por isso são utilizadas em diversas aplicações, especialmente para dispositivos eletroeletrônicos ${ }^{1}$. Já ligas de $\mathrm{Ni}-\mathrm{W}$ são conhecidas por sua excelente resistência a corrosão em alta temperatura, elevada dureza e propriedades magnéticas ${ }^{1}$. Em estudos sobre a liga ternária de $\mathrm{Ni}-\mathrm{Co}-\mathrm{W}$ foi possível combinar as propriedades desses metais e formar um revestimento resistente à corrosão e com melhores propriedades mecânicas ${ }^{1}$. Neste trabalho, propôs-se avaliar a densidade de corrente elétrica - que pode influenciar diretamente na textura e morfologia da superfície do revestimento ${ }^{1}$ - e a agitação do banho eletrolítico para a síntese da liga ternária de $\mathrm{Ni}-\mathrm{Co}-\mathrm{W}$, utilizando substratos de aço.

\section{Resultados e Discussão}

Para a eletrodeposição, o aço foi colocado como cátodo de uma célula eletrolítica submerso em um banho eletrolítico; como contraeletrodo foi utilizada uma malha de platina. Os ensaios foram realizados à temperatura ambiente, utilizando um potenciostato na forma galvanostática. As variáveis avaliadas foram a densidade de corrente e a rotação catódica. Os valores de eficiência obtidos são descritos na Tabela 1.

Tabela 1. Planejamento fatorial $2^{2}$ da liga Ni-Co-W e suas respectivas eficiências.

\begin{tabular}{cccc}
\hline Exp. & Corrente $(\mathrm{mA})$ & Rotação (rpm) & Eficiência (\%) \\
\hline 1 & 400 & 20 & 26,37 \\
2 & 560 & 20 & 20,70 \\
3 & 400 & 60 & 26,77 \\
4 & 560 & 60 & 22,51 \\
5 & 480 & 40 & 24,55 \\
6 & 480 & 40 & 24,16 \\
7 & 480 & 40 & 23,44 \\
\hline \hline
\end{tabular}

Os maiores valores de eficiência foram obtidos com baixa densidade de corrente, sendo a eficiência máxima $26,77 \%$, usando a maior rotação. Utilizou-se o método de superfície de resposta para aperfeiçoar a eficiência: a modelagem foi feita ajustando o modelo linear, seguido do deslocamento da rotação catódica (em unidades codificadas). Os valores foram convertidos para as unidades originais para determinar os novos níveis dos fatores. Após um novo planejamento, o valor máximo de eficiência foi 43,07\%. Em relação à composição química da liga, a porcentagem de W diminuiu com o aumento da densidade de corrente, enquanto a porcentagem de $\mathrm{Ni}$ aumentou com o aumento da densidade de corrente - como já previsto ${ }^{1}$. Pela análise por DRX, observou-se a formação de um revestimento cristalino em todos os experimentos. A morfologia do revestimento apresentou nódulos na superfície, sendo estes menos numerosos à densidades de corrente de até $50 \mathrm{~mA} / \mathrm{cm}^{2}$, como na Figura 1a. Para densidades de corrente maiores, a presença de nódulos foi maior, conforme na Figura $1 \mathrm{~b}$.

Figura 1. Micrografia da liga metálica Ni-Co-W do (a) Exp.

1 e (b) Exp. 4, da Tabela 1; ampliação de 5.000 vezes.
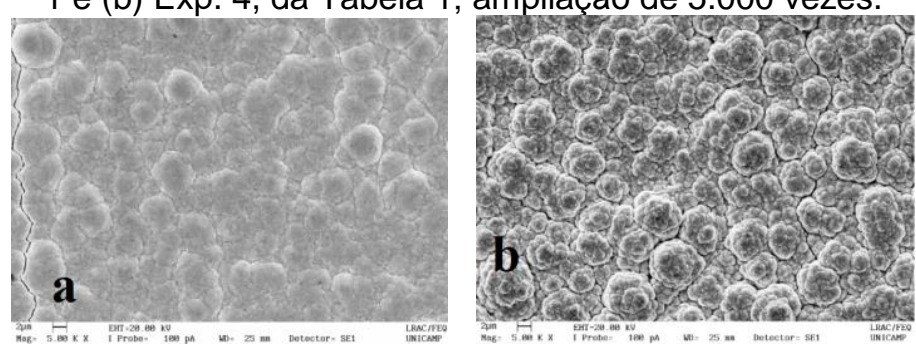

\section{Conclusões}

A liga Ni-Co-W apresentou boa aderência ao substrato, sendo a eficiência diretamente influenciada pela densidade de corrente. A estrutura dos revestimentos obtidos foi cristalina. Na análise das micrografias, verificou-se que, para densidades de corrente acima de $50 \mathrm{~mA} / \mathrm{cm}^{2}$, não houve variações expressivas da morfologia do revestimento. Concluiu-se que elevadas densidades de corrente provocaram poucas alterações ao nível estrutural, morfológico e de eficiência faradaica para obtenção das ligas de $\mathrm{Ni}-\mathrm{Co}-\mathrm{W}$.

\section{Agradecimentos}

Ao CNPq e ao LabPEA

1FARZANEH, M. A. et al. Effects of Co and W alloying elements on the electrodeposition aspects and properties of nanocrystalline Ni alloy coatings. Applied Surface Science, v. 257, p. 5919-5926, 2011. 